Therapeutics and Technology Assessment Subcommittee of the American Academy of Neurology. Neurology September (1 of 2) 2005;65:668-675). (Reprints: American Academy of Neurology, 1080 Montreal Ave, St Paul, MN 55116).

COMMENT. An elevated serum PRL is specific for GTCS and CPS, and may be used to differentiate these epileptic from psychogenic nonepileptic seizures. A positive test may be useful as a substitute for video-EEG monitoring when this is unavailable. The test has a low sensitivity, and a negative result cannot be considered diagnostic of a psychogenic seizure. In addition to epileptic seizures, other events, including syncope, pregnancy, hypothyroidism, and various drugs may be associated with elevated PRL. PRL sampling should be obtained within 10 and 20 minutes after a suspected seizure, and a return to a baseline level is reached after an interval of 6 hours. Further studies will be necessary to establish the value of the test in young children and in neonates.

\title{
NOVEL GENETIC LOCUS FOR GENERALIZED TONIC CLONIC EPILEPSY WITHIN THE JUVENILE MYOCLONIC EPILEPSY SYNDROME
}

A genome-wide scan of a large family with juvenile myoclonic epilepsy (JME), seen at the All India Institute of Medical Sciences, New Delhi, was conducted to test an hypothesis that 2 loci, one predisposing to generalized tonic clonic seizures (GTCS) and a second to myoclonic seizures (MS), would be present within the JME syndrome. A new locus for GTCS was identified at 10q25-q26, and analyses of this locus performed in 10 additional JME families showed evidence for linkage in 4 . The findings show that this novel locus confers susceptibility to GTCS within the syndrome of JME. (Puranam RS, Jain S, Kleindienst AM et al. A locus for generalized tonic-clonic seizure susceptibility maps to chromosome 10q25-q26. Ann Neurol September 2005;58:449-458). (Respond: Dr James O McNamara, Department of Neurobiology, 401 Bryan Research Building, Research Drive, Box 3676, Duke University Medical Center, Durham, NC 27710).

COMMENT. These findings show that a locus on chromosome 10q25-q26 confers susceptibility to GTCS within the genetic syndrome of juvenile myoclonic epilepsy. In support of the theory of two loci, one for GTCS and another for MS, within the IME syndrome is the clinical pattern of different ages of onset for these seizures. The syndrome commonly presents with absence seizures between 5 and 16 years, myoclonic jerks follow about 4 years later, usually around age 15 years, and GTCS are the last to appear, and mainly on awakening (Grunewald RA et al. Arch Neurol 1993;50:594-598; Ped Neur Briefs June 1993).

\section{EXPERT CONSENSUS ON PHOTOSENSITIVE EPILEPSIES}

The literature and data on photic- and pattern-induced seizures were reviewed and a consensus was developed of risk factors for visually evoked seizures, at a workshop of the Epilepsy Foundation of America, in Alexandria, VA, August 2004. Photosensitive individuals are at risk of seizures from flickering or intermittent images and certain patterns 
encountered in television, video games, computer screens, motion pictures, advertising displays, rock concerts, theater, opera, dance halls, nightclubs, and architectural materials. To reduce the risk of provoking seizures, the following recommendations were made for the design of flashing images or regular patterns: Potential hazards to be avoided include 1) a flash of luminance $>20 \mathrm{~cd} / \mathrm{m} 2$, at a frequency $>3 \mathrm{~Hz}$, in $25 \%$ of screen area at viewing distance; 2) a transition to and from saturated red; 3 ) a striped pattern, with more than 5 lightdark pairs of stripes; 4) stripes that change direction, oscillate, flash, or reverse in contrast; and 5) a pattern of $>8$ pairs of stripes that is unchanging or drifting in one direction. (Harding G, Wilkins AJ, Erba G et al. Photic- and pattern-induced seizures: Expert consensus of the Epilepsy Foundation of America Working Group. Epilepsia September 2005;46:1423-1425). (Reprints: Dr RS Fisher, Stanford Medical Center, Room A343, 300 Pasteur Drive, Stanford, CA 94305).

COMMENT. Visually induced seizures may be generalized or focal, idiopathic or syniptomatic, or represent a pure, reflex photosensitive epilepsy (Guerrini R et al. Epilepsia 2004;45 (Suppl 1):14-18; Ped Neur Briefs Jan 2004;18:7). For further articles on photosensitive seizures, see Ped Neur Briefs 2004;18:36-37.

The background information obtained from a review of the literature and used by the EFA for their consensus recommendations is outlined by Fisher RS et al. Epilepsia Sept 2005;46:1426-1441.

Reflex seizures in children with malformations of cortical development tend to be refractory to anticonvulsant medications but may respond to surgical resection of focal lesions. (Palmini A et al. Epilepsia 2005;46:1224-1234).

\section{EFFECT OF COMBINED KETOGENIC DIET AND VALPROATE TREATMENT FOR INTRACTABLE SEIZURES}

The safety and tolerability of ketogenic diet (KGD) and valproate (VPA) cotherapy in the treatment of intractable seizures were evaluated retrospectively at the Massachusetts General Hospital, Boston. The ages of a total of 71 patients were 7 months to 20 years (mean, 7 years). All had received the KGD, and 24 were treated concomitantly with VPA. Two patients $(2.8 \%)$ developed pancreatitis after 4 months on the KGD alone. Adverse events affecting patients equally in the KGD/VPA and non-VPA groups included symptomatic acidosis $(39.4 \%)$, nausea and vomiting $(23.9 \%)$, hypertriglyceridemia $(21.1 \%)$, infections (eg otitis media, URI) in $21 \%$, lethargy (18.3\%), and behavioral abnormalities and irritability (15.5\%). Renal calculi affected $6.4 \%$ of the KGD alone group. Elevations in liver function tests occurred in 2 patients taking VPA cotherapy. Carnitine supplements were given to 19 patients on the diet, and no patient reported symptoms of carnitine deficiency. Treatment was continued at 1 year in 32 patients, 11 taking the combined KGD and VPA therapy. Reductions in seizure frequency at 1 year were $47 \%$ with $>90 \%$ reduction, $25 \%$ with $50-90 \%$ reduction, and $29 \%$ with $<50 \%$ reduction. Seizure control was not significantly different in the KGD and VPA cotherapy groups and was unrelated to the KGD fat to carbohydrate ratio. The majority received a ratio of $4: 1$ at initiation of the diet, 17 had ratios of 3.5-3.9:1, and 12, ratios of 3-3.4:1, fat to carbohydrate + protein. Anticonvulsant regimens were adjusted or eliminated during the trial of the KGD. The authors consider KGD and VPA cotherapy to be safe and effective in the management of refractory pediatric epilepsy. (Lyczkowski DA, 